Military Technical College Kobry El-Kobbah, Cairo, Egypt

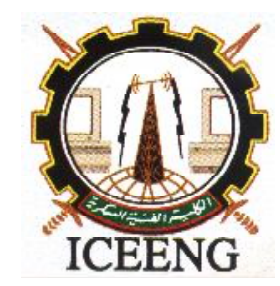

$10^{\text {th }}$ International Conference on Electrical Engineering ICEENG 2016

\title{
Laser Indirect Exposure Method for Treatment of Nanomaterials
}

$$
\text { By }
$$

\author{
Hebatalrahman *
}

\begin{abstract}
:
Method to improve the mechanical properties of nano materials, micromaterials and short fibers by indirect exposure to laser irradiations. The method was done by dipping powder materials in transparent plastics to allow the passage of a laser beam through it without being absorbed or interact with transparent material.

The laser affect the structure of powder and improve properties, After exposure organic solvent is used to dissociate the transparent plastics, the treated nanomaterials or short fibers were collected. The method is a physical process free of pollutants and exhaust, it do not cause economic losses in the amount of material treated.
\end{abstract}

\section{Keywords:}

laser irradiation, nano materials, short fibers,

* Dr.eng. Consultant in materials sciences \& materials applications, Egypt hebatalrahman11@yahoo.com, $\quad$ hebatalrahman11@gmail.com 


\section{Introduction:}

Fibre $^{[1]}$ is a class of materials that are continuous filaments or discrete elongated pieces, similar to lengths of thread. Human uses for fibers are diverse. They can be spun into filaments, thread, string or rope. They can be used as a component of composite materials. They can also be matted into sheets to make products such as paper or felt. Fibers are often used in the manufacture of other materials [1].

Synthetic or man-made fibers may come from natural or synethetic materials such as petrochemicals. Many types of fiber are manufactured from natural cellulose, including rayon, modal, and the more recently developed Lyocell. Cellulose-based fibers are of two types, regenerated or pure cellulose such as from the cupro-ammonium process and modified or derivitized cellulose such as the cellulose composite with superior structural strength and flexural modulus.

It was originally developed to replace wood flooring used for truck bed and buses. After its successful entry in the automotive industry, other applications have also been tested and found to outperform traditional materials. The result is a strong, lightweight, perfectly straight and high performance that is durable and capable in terms of weatherability, flammability and machinability[ 2-4].

Nanocrystalline materials ${ }^{1}$ are three-dimensional solids composed of nanometresized grains, or crystallites. Because of their unique structure, which is characterized by ultrafine grains and a rather high density of crystal-lattice defects, these materials have extraordinary fundamental properties that could be exploited to make 'next-generation' superstrong metals, ductile ceramics and wear-free materials. A nanostructure is an object of intermediate size between microscopic and molecular structures[3]. In describing nanostructures it is necessary to differentiate between the number of dimensions on the nanoscale. Nanotextured surfaces have one dimension on the nanoscale, only the thickness of the surface of an object is between 0.1 and $100 \mathrm{~nm}$. Nanotubes have two dimensions on the nanoscale, the diameter of the tube is between 0.1 and $100 \mathrm{~nm}$; its length could be much greater [5-7]. Finally, spherical nanoparticles have three dimensions on the nanoscale, the particle is between 0.1 and $100 \mathrm{~nm}$ in each spatial dimension[8-10]. The terms nano-particles and ultrafine particles (UFP) often are used synonymously although UFP can reach into the micrometer range. The term 'nanostructure' is often used when referring to nano technology [11]. 
Nanofibers are defined as fibers with diameters less than 100 nanometers[1215]. In the textile industry, this definition is often extended to include fibers as large as $1000 \mathrm{~nm}$ diameter. ${ }^{[2]}$ They can be produced by interfacial polymerization, electrospinning, and force spinning. Carbon nanofibers are graphitized fibers produced by catalytic synthesis [16-17].

Nanoparticles often possess unexpected optical properties as they are small enough to confine their electrons and produce quantum effects. ${ }^{[29]}$ For example gold nanoparticles appear deep-red to black in solution. Nanoparticles of yellow gold and grey silicon are red in color. Gold nanoparticles melt at much lower temperatures $\left(\sim 300^{\circ} \mathrm{C}\right.$ for $2.5 \mathrm{~nm}$ size) than the gold slabs $\left(1064{ }^{\circ} \mathrm{C}\right) ; .{ }^{[30]}$ Absorption of solar radiation is much higher in materials composed of nanoparticles than it is in thin films of continuous sheets of material. In both solar PV and solar thermal applications, controlling the size, shape, and material of the particles, it is possible to control solar absorption [18-20]. other sizedependent property changes include quantum confinement in semiconductor particles, surface plasmon resonance in some metal particles and super para magnetism in magnetic materials, Which would appear the changes in physical properties. Ferromagnetic materials smaller than $10 \mathrm{~nm}$ can switch their magnetisation direction using room temperature thermal energy, thus making them unsuitable for memory storage [21-23].

\section{Experimental work:}

\section{Material preparation}

E-fiber glass Ownes corning 731ED 1/32". which is mechanically cut the fiber size is length to diameter ratio $\mathrm{L} / \mathrm{d}=50$ (cylindrical particles) and $\mathrm{L} / \mathrm{d}=1$ (spherical particles). Table (1) shows chemical composition of fiber glass type -E. Figure(1) shows the phase diagram of the fiber glass type -E

Table (1) Chemical composition of fiber glass type -E [24]

\begin{tabular}{|c|c|c|c|c|c|}
\hline $\mathrm{SiO}_{2}$ & $\mathrm{Al}_{2} \mathrm{O}_{3}$ & $\mathrm{CaO}$ & $\mathrm{MgO}$ & $\begin{array}{c}\mathrm{Na}_{2} \mathrm{O} \\
\mathrm{K}_{2} \mathrm{O}\end{array}$ & $\mathrm{Ba}_{2} \mathrm{O}_{2}$ \\
\hline 52.4 & 14.4 & 17.2 & 4.6 & 0.8 & 10.6 \\
\hline
\end{tabular}




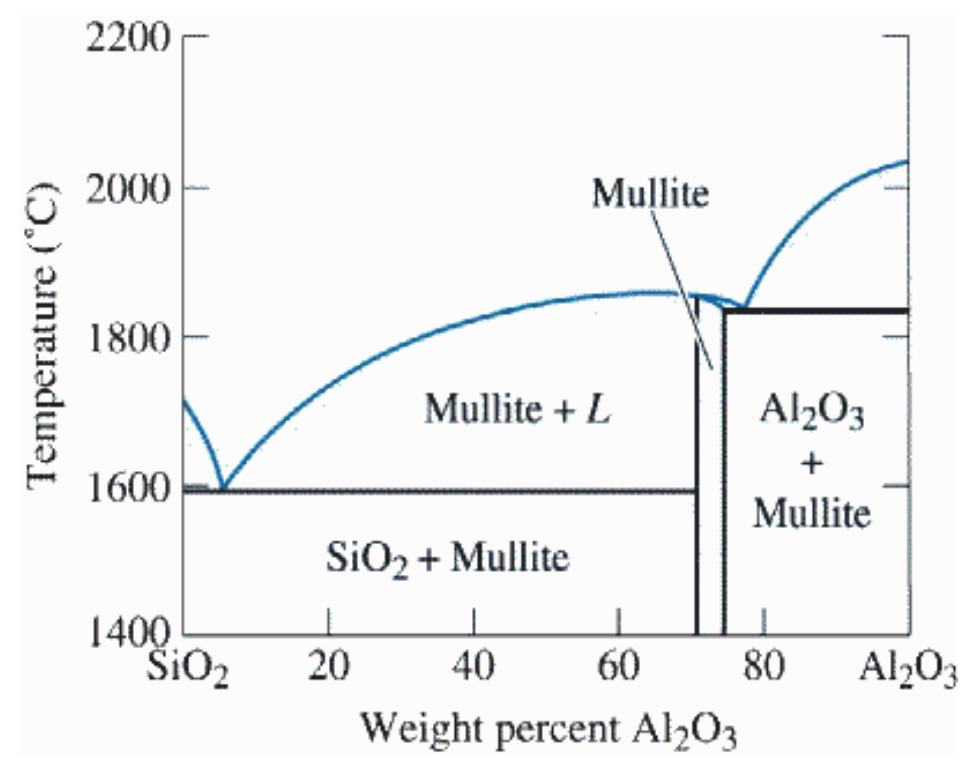

Figure (1) the phase diagram of the fiber glass type -E [25]

\section{Transparent material}

the transparent material is plastic, it does not absorb the laser wavelengths used in the test and dissolved after the process by mixture of organic solvents. The mixture composition is shown in table (2).

\section{Dissociation of transparent material}

It can be dissolved in a number of organic solvents. n-hexane, n-heptane, cyclohexane, benzene, toluene

Table (2) Organic mixture for Dissociation of transparent material[26]

\begin{tabular}{|l|l|l|l|}
\hline Solvent & Chemical formula & Boiling point & Density \\
\hline Hexane & $\mathrm{CH}_{3}-\mathrm{CH}_{2}-\mathrm{CH}_{2}-\mathrm{CH}_{2}-\mathrm{CH}_{2}-\mathrm{CH}_{3}$ & $69^{\circ} \mathrm{C}$ & $0.655 \mathrm{~g} / \mathrm{ml}$ \\
\hline Benzene & $\mathrm{C}_{6} \mathrm{H}_{6}$ & $80^{\circ} \mathrm{C}$ & $0.879 \mathrm{~g} / \mathrm{ml}$ \\
\hline Toluene & $\mathrm{C}_{6} \mathrm{H}_{5}-\mathrm{CH}_{3}$ & $\mathbf{1 1 1}{ }^{\circ} \mathbf{C}$ & $0.867 \mathrm{~g} / \mathrm{ml}$ \\
\hline Cyclohexane & $\mathrm{C}_{6} \mathrm{H}_{12}$ & $81^{\circ} \mathrm{C}$ & $0.779 \mathrm{~g} / \mathrm{ml}$ \\
\hline
\end{tabular}

\section{Laser Irradiation}

Samples used in this investigation were in a shape of disk of $25 \mathrm{~mm}$ diameter and $7 \mathrm{~mm}$ length. The irradiation is done on both sides of the samples and in different 
positions to cover all area of the sample and achieve homogeneous surface suitable for testing .The different lasers irradiated samples at different conditions were examined before and after laser irradiation and the effect of laser was determined.

CW argon ion laser (innova400) which have power of 25 watts multi-line wavelength from $514.5 \mathrm{~nm}$ to $465.5 \mathrm{~nm}$, the power used in the experiment is 1 watt.

\section{Raman Spectroscopy}

The behaviour of the material was studied by variation of the modes obtained from FT (IR) Raman spectrum. The results were obtained using Brucker FTIR Raman spectrometer using Nd-YAG laser power of $500 \mathrm{MW}$ as source of excitation. After irradiation of sample with lasers the spectra were obtained in the range 400 to $4000 \mathrm{~cm}^{-1}$. The samples were measured by fixing it to holder and placed in front of the beam [27].

\section{Hardness}

The hardness of the specimens were measured by using means of Barcol impression according to ASTM-D2583, the indentor cone with $26^{\circ}$ and $0.157 \mathrm{~mm}$, the sample must have smooth and polished surface with thickness not more than $1.5 \mathrm{~mm}$, the load ranges from $6.8 \mathrm{~kg}$ to $4.5 \mathrm{~kg}$ each hardness value is an average of 29 reading for every specimen ( 5 specimen at each condition were examined). The measurements are good up to $\pm 6 \%$.

\section{The laser effect along the length of the specimen}

The laser effect along the distance was evaluated, the specimen used for this purpose was $20 \mathrm{~mm}$ diameter and $13 \mathrm{~mm}$ length irradiated by Argon ion laser $(514 \mathrm{~nm}-1$ watt-10 second) in the center of the specimen, it was separated vertically into two parts, every part is fixed on holder (average of 4 specimen were considered at each condition). Barcoul hardness was measured every $3 \mathrm{~mm}$ along the length of the specimen according to ASTM-D2583 test procedure explained above, the results were plotted on X-Y plan (distance -hardness) and the laser effect distributed along the length of the specimen were evaluated.

\section{Power measurements}

The PM-450B power meter is used for power measurements at wavelength $632.8 \mathrm{~nm}$, the calibration is done at the wavelength in the study range $514 \mathrm{~nm}$ by taking the meter reading and multiple by the appropriate spectral sensitivity value according to the calibration cure as shown in Figure (2). The PM-450B power meter is used in 
measurements by setting the full scale meter sensitivity one position beyond the anticipated maximum power level, adjust the detector position for maximum meter output reposition the meter switch to take advantage of the maximum meter deflection, this will ensure maximum accuracy in the measurement the output impedance $200 \mathrm{Ohms}$ or less on all ranges. To achieve temperature sensitivity, the instrument is calibrated at $20^{\circ} \mathrm{C}$, the difference in the range $\pm 5^{\circ}$ will affect the accuracy by less than $3 \%$.

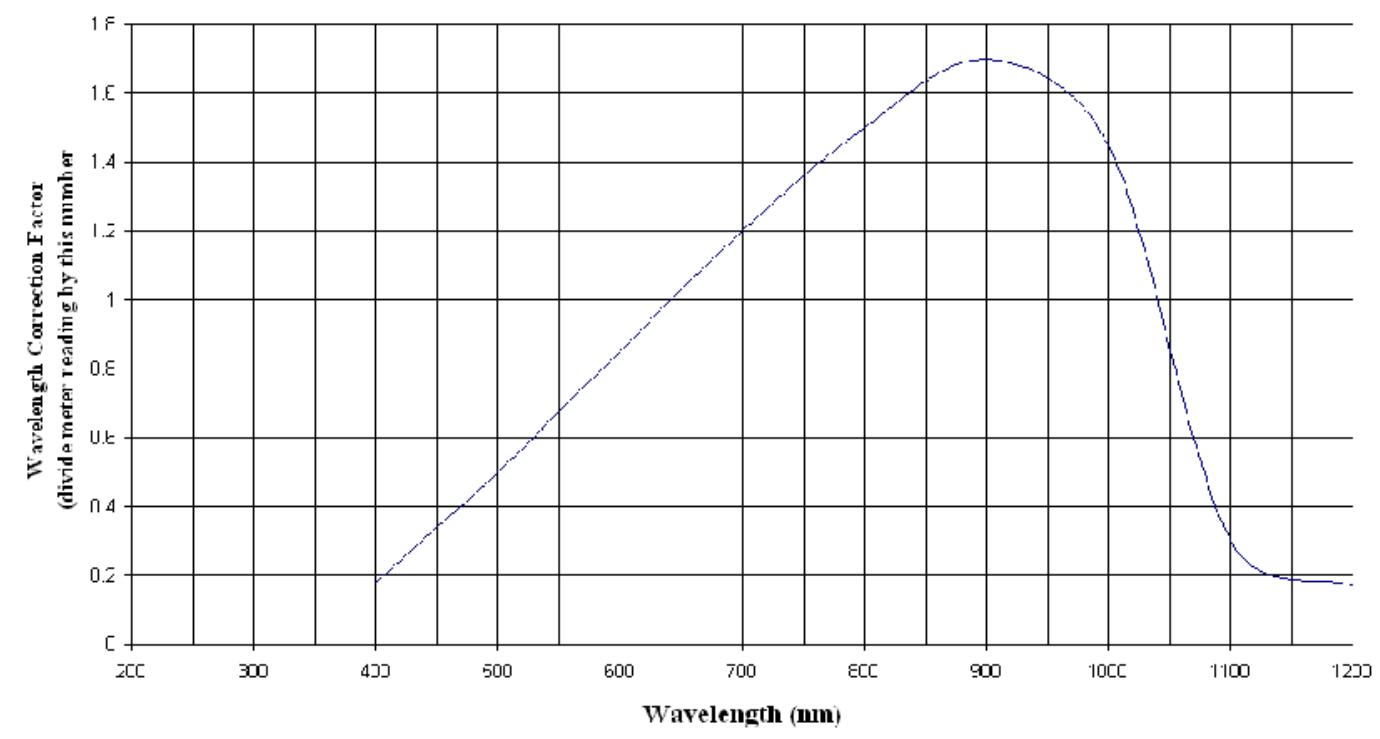

Fig(2)Relative spectrum response and wavelength correction factor

\section{Results \& discussions:}

\section{Spectroscopic analysis}

To determine the effect of laser on the particles used in our study range the raman spectroscopy technique is used to evaluate the structure change in micro and nano particles due to Argon laser interaction with matter. With Raman spectroscopy a laser beam is used to irradiate a spot on the sample under investigation. The scattered radiation produced by the Raman effect contains information about the energies of molecular vibrations and rotations, and these depend on the particular atoms or ions that comprise the molecule, the chemical bonds connect them, the symmetry of their molecule structure, and the physico-chemical environment where they reside. The principle is based on the fact that bonds and groups of bonds vibrate at characteristic frequencies. A molecule that is exposed to infrared rays absorbs infrared energy at frequencies which are characteristic to that molecule. Figure (3)shows the raman spectrum for transparent material before and after laser absorption of Argon laser 
$507 \mathrm{~nm}$. In the first step of the work the transparent material PMMA is tested for laser absorption at the same laser wavelength and same irradiation conditions and there is no change may be recorded in the characteristic and behavior of resin. This resin is used as binding media for micro and nano particles, the laser effect can be recorded as shown in figure (4) which shows The raman spectrum for spherical micro and nano particles before and after laser absorption of Argon laser 507nm. The particles is randomly distributes inside the structure in all directions and in all positions. at higher concentrations of micro and nano particles the change in the peak intensity and shape. Nano-particles often possess unexpected optical properties as they are small enough to confine their electrons and produce quantum effects.

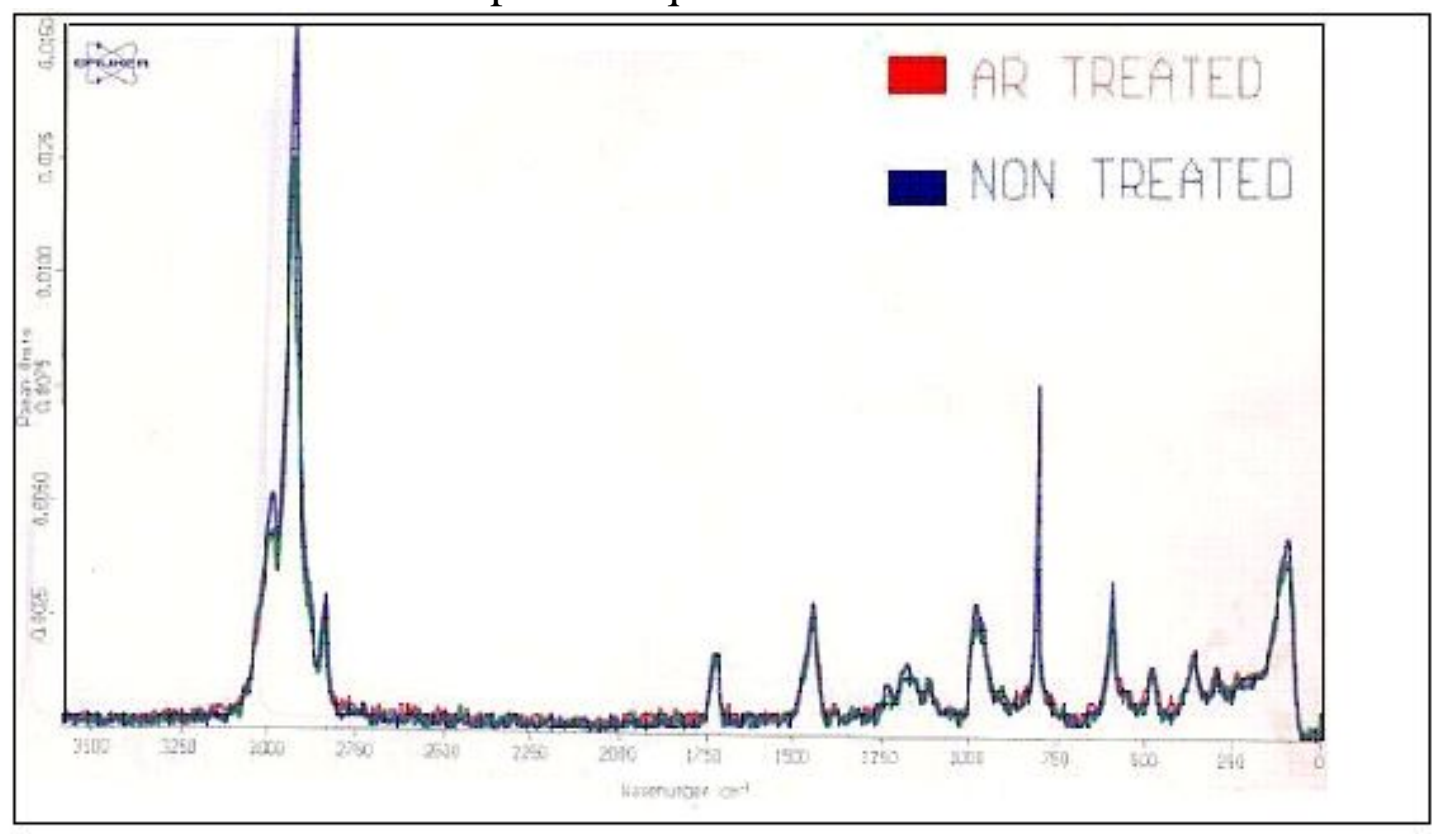

Fig (3)The raman spectrum for transparent material before and after laser absorption of Argon laser 507nm 


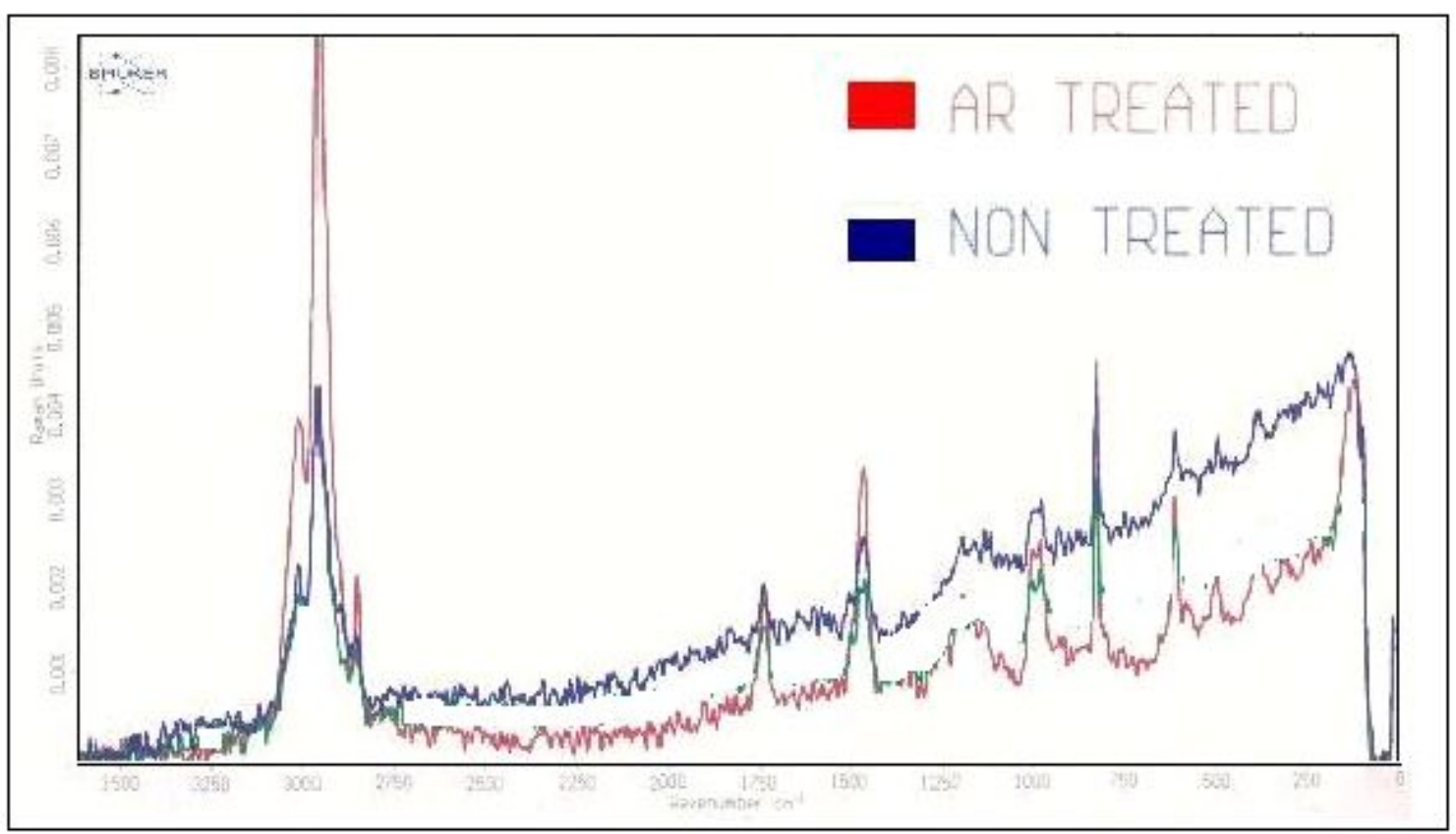

Fig (4)The raman spectrum for spherical micro and nano particles before and after laser absorption of Argon laser 507nm.

\section{Mechanical properties}

\section{Hardness}

The change in the structure of micro and nano particles due to the laser irradiation process leads to improve in the mechanical properties of the particles which can be determined by measuring the laser effect along the length of the specimen. The hardness value was measured along discrete distances from the source, the specimen used for this purpose was $20 \mathrm{~mm}$ diameter and $13 \mathrm{~mm}$ length irradiated by Argon ion laser $(514 \mathrm{~nm}$ 1watt-10 second). The hardness were evaluated at different volume fraction of micro and nano particles. the particles volume fraction ranges from $0 \%$ which is the transparent material without any additives, to $65 \%$. which is the maximum value of particles can be impeded inside the transparent material.

The effect of the shape and size of the micro and nano particles on the absorption of laser irradiation were recorded for spherical and cylindrical particles. Figure (5) and figure (6) show the variation of the Hardness due to absorption variation along the sample of spherical particles and cylindrical particles respectively. The effect of laser irradiation was pronounced in front of the laser beam and decreased in the range from $9 \mathrm{~mm}$ to $12 \mathrm{~mm}$ to reach minimum value at $15 \mathrm{~mm}$. 


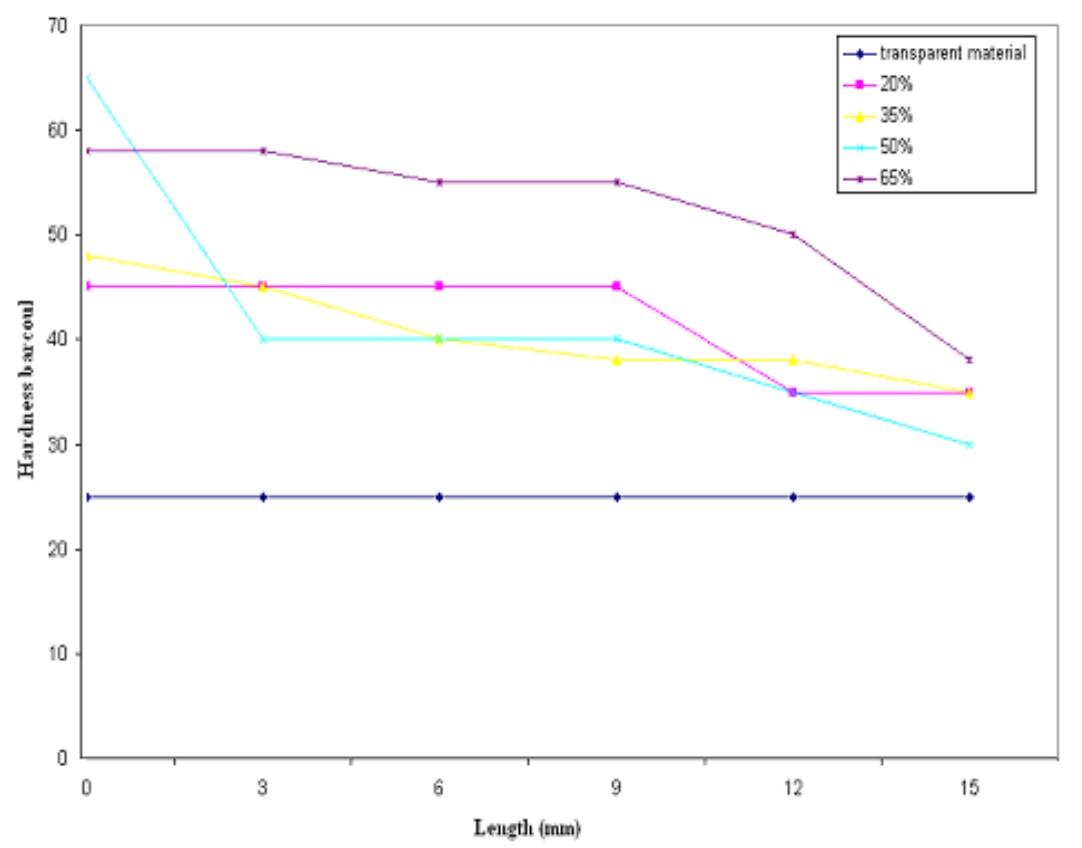

Fig(5) The variation of the Hardness due to absorption variation along the sample of spherical particles

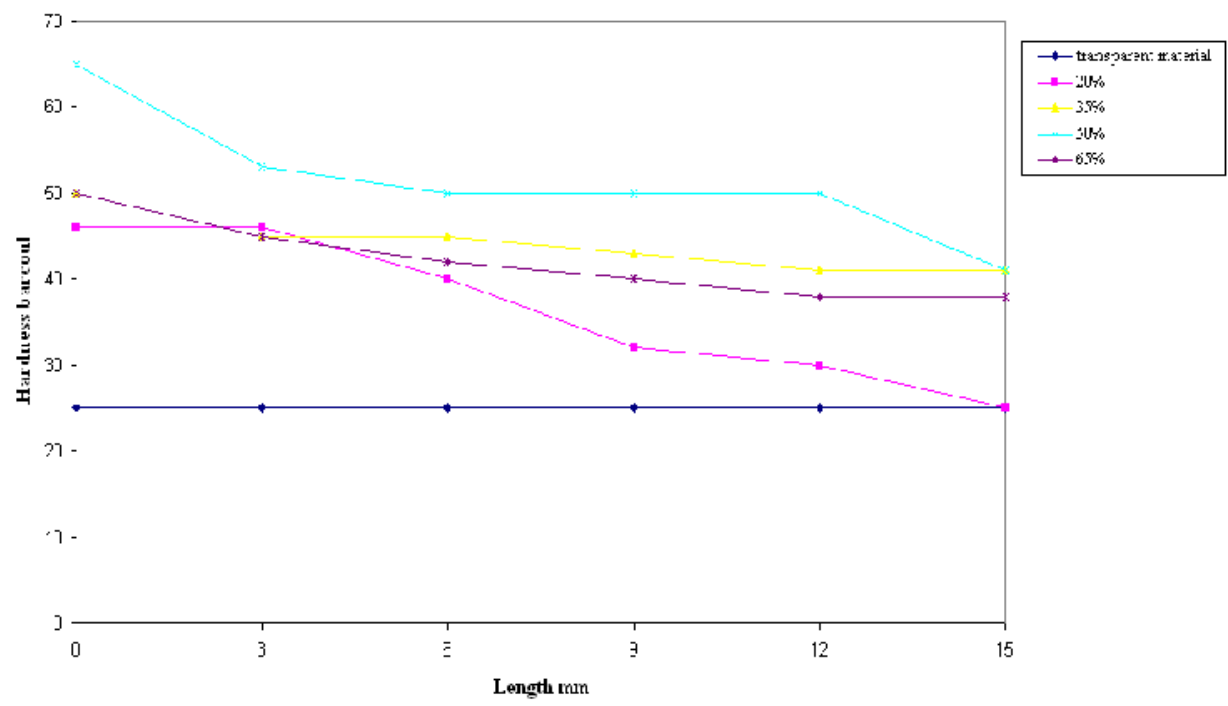

Fig(6) The variation of the Hardness due to absorption variation along the sample of cylindrical particles

\section{Power measurements}

The output power after the laser go through the treated material was evaluated by power meter. Table (3) shows the output power of the laser irradiated samples at different 
particles shape and volume fractions, the absorption rate in spherical particles was less than cylindrical one, while the increase in volume fraction of particles decrease the output power and increase absorption rate. the increase in absorption rate improve the mechanical properties (hardness) value as explained above in figure (5) and figure(6). Absorption of laser irradiation is much higher in materials composed of nano-particles controlling the size, shape, and material of the particles, it is possible to control laser absorption [27]. The high surface area to volume ratio of nano-particles provides a tremendous driving force for diffusion, especially at elevated temperatures irradiation can take place at lower temperatures, over shorter time scales than for larger particles.

Table (3) the output power of the laser irradiated samples

\begin{tabular}{|l|l|l|l|l|l|}
\hline $\begin{array}{l}\text { Fiber } \\
\%\end{array}$ & $\begin{array}{l}\text { Length to diameter ratio } \\
\text { L/D }\end{array}$ & Scale & $\begin{array}{l}\text { Distance } \\
\text { cm }\end{array}$ & Value & $\begin{array}{l}\text { Modified } \\
\text { value }\end{array}$ \\
\hline 0 & 0 & 1 & $0.5: 0.6$ & 7.8 & 14.9 \\
\hline 17 & 1 & 1 & $0.5: 0.6$ & 7.3 & 14.6 \\
\hline 35 & 1 & 1 & $0.5: 0.6$ & 3.8 & 7.6 \\
\hline 50 & 1 & 1 & $0.5: 0.6$ & 2.8 & 5.6 \\
\hline 65 & 1 & 1 & $0.5: 0.6$ & 1.3 & 2.6 \\
\hline 17 & 50 & 1 & $0.5: 0.6$ & 4.3 & 8.6 \\
\hline 35 & 50 & 1 & $0.5: 0.6$ & 2.1 & 4.2 \\
\hline 50 & 50 & 1 & $0.5: 0.6$ & 1.5 & 3.0 \\
\hline 65 & 50 & 1 & $0.5: 0.6$ & 0.7 & 1.4 \\
\hline
\end{tabular}

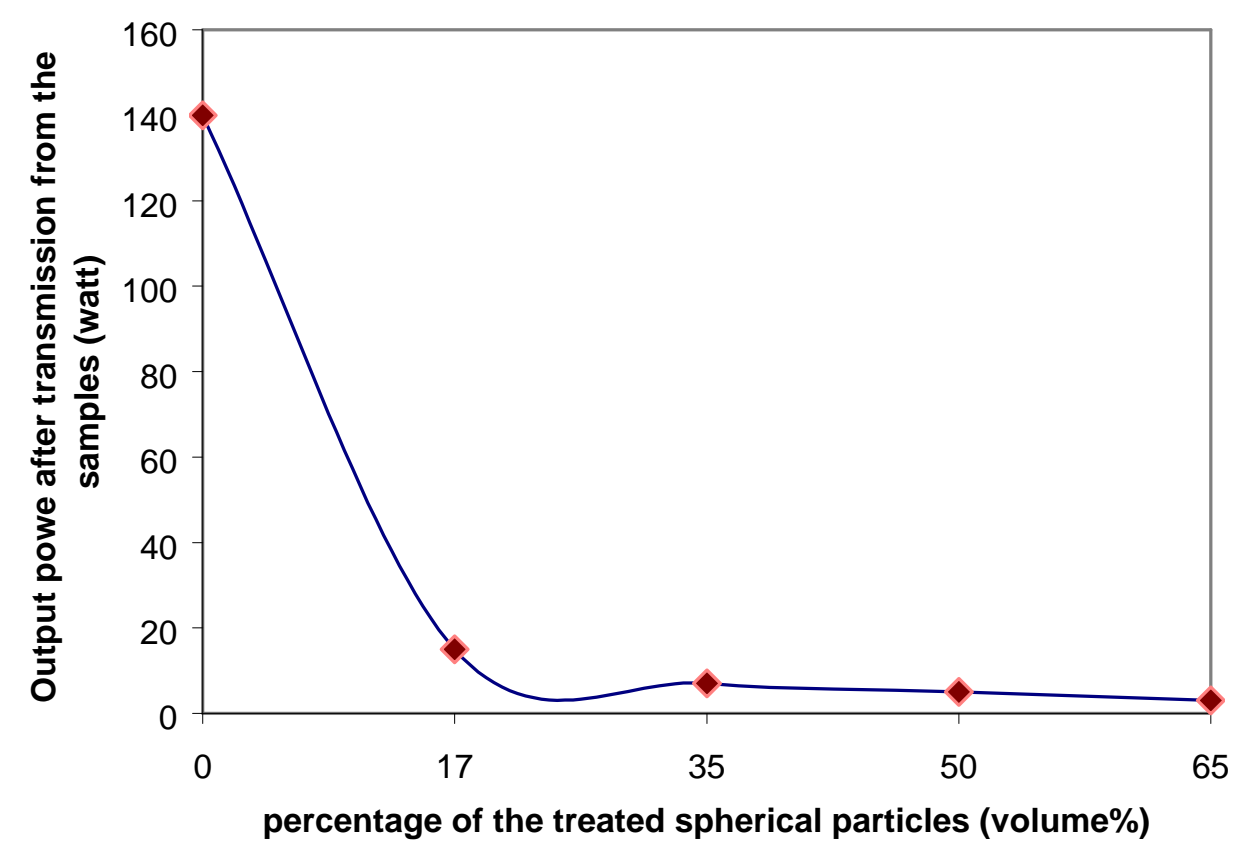

Fig (7) The laser output power after absorption by micro and nano particles at different volume fractions of particles 


\section{Conclusions:}

1. The spectroscopy analysis before and after laser irradiation at power of $500 \mathrm{MW}$ as source of excitation.

Raman spectra shows the following types of changes with irradiation-:

a-The disappearance of same peak.

b-Shift in the peak position.

c-The dependence of some parameters in addition to the activation energy and crystalline on the irradiation power shows different behavior.

$\mathrm{d}$-The fiber glass is the element which absorb laser irradiation, the zero percentage fiber glass samples produces almost no change in the Raman spectrum before and after irradiated.

2. Transparent material allow the laser light to go throw the structure easily, but this type of polymers do not affected by absorption of ultra violet light so it is seem to be suitable binding material.

3. There is reasonable change in the Raman spectrum of the samples which have the same length to diameter ratio (size) but different amount of fibers.

4. The laser energy is very high, this high energy rating is stored inside the material, This is the main cause of improvement in the mechanical properties.

5. the mechanism of laser irradiation as a tool of improving mechanical properties is similar to the cold working mechanism which store mechanical energy in the atoms and the mechanical properties is improved but in lasers the photon energy is absorbed by atoms and stored inside the structure and also cause significant improvement in the mechanical properties.

\section{References:}

1. Freestone I, Meeks N, Sax M, Higgitt C. The Lycurgus Cup - A Roman nanotechnology. Gold Bulletin 2007; 40(4) 270-77.

2. Brown M.S., Arnold C.B. Fundamentals of Laser-Material Interaction and Application to Multiscale Surface Modification. In: Sugioka K., Meunier M., PiqueA (ed.) Laser Precision Microfabrication. Springer Series in Materials Science: Springer Berlin Heidelberg; 2010. p. 91- 120.

3. https://web.stanford.edu/dept/EHS/prod/researchlab/IH/nano/docs/Working_Safely_ with_Engineered_Nanomaterials.pdf.

4. http://www.nanowerk.com/nanotechnology/introduction/introduction_to_nanotechno logy_4.php.

5. https://nccr.iitm.ac.in/2011.pdf.

6. http://www.fi.tartu.ee/ rynno/raamat/Introduction\%20in\%20nanomaterials-sisu.pdf 
7. Johnson-mcdaniel D, Barrett CA, Sharafi A, Salguero Tt. Nanoscience of an Ancient Pigment, Journal of American Chemical Society 2013; 135(5) 1677-1679. 4.

8. Maiman TH. Stimulated Optical Radiation in Ruby. Nature 1960; 187 493-94.

9. Shirk MD, Molian PA. A review of ultrashort pulsed laser ablation of materials. Journal of Laser Applications 1998; 10(1) 18-28.

10. Yang GW. Laser ablation in liquids: Applications in the synthesis of nanocrystals. Progress in Materials Science 2007; 52 (4) 648-98.

11.Zeng H, Du X-W, Singh SC, Kulinich SA, Yang S, He J, Cai W. Nanomaterials via Laser Ablation/Irradiation in Liquid: A Review. Advanced Functional Material 2012; 22(7) 1333- 1353.

12. Bäuerle D. Thermal, Photophysical, and Photochemical Processes. In: Laser Processing and Chemistry: Springer Berlin Heidelberg; 1996. p. 13-38.

13. Nanomaterials Handbook. Ed. by Yu.Gogotsi. Taylor \& Francis Group, LLC, 2006.

14.M. S. Dresselhaus, P.C.Eklund. Phonons in carbon nanotubes// Advances in physics. - 2000. - V.49, N6. - P. 705-814.

15.H.Gleiter. Nanostructured materials: basic concepts and microstructures// Acta Metallurgica. - 2000. - 48, N1. - P. 1-29.

16. J.D.Joannopoulos, P.R.Villeneuve, S.Fan. Photonic crystals: putting a new twist on light// Nature. - 1997. - 386. - P. 143-149.

17. V.V. Pokropivny. Noncarbon nanotubes. Review// Powder Metallurgy and Metal Ceramics. I. Methods of synthesis V.40, Issue 9/10, p. 485-496 (2001).

18.V.V. Pokropivny. Two-dimensional nanocomposites. Review// Powder Metallurgy and Metal Ceramics. I. Types and fabrication V. 41, Issue 5/6, p. 264-272 (2002)

19. Nawy, Edward G. (2001), Fundamentals of high-performance concrete (2 ed.), John Wiley and Sons, p. 310, ISBN 978-0-471-38555-4.

20.J E Gordon (28 March 1991). The New Science of Strong Materials: Or Why You Don't Fall Through the Floor. Penguin Books Limited. ISBN 978-0-14-192770-1. Retrieved 12 June 2012.

21. Toxicological Profile for SynthethicVitreous Fibers (U.S. Department of Health and Human Services, Public Health Services, Agency for Toxic Substances and Disease Registry), September 2004, pp. 5, 18

22. Charles William Jameson, "Comments on the National Toxicology Program's Actions In Removing Biosoluble Glass Wool Fibers From The Report On Carcinogens," September 9, 2011.

23. NRC Subcommittee on Manufactured Vitreous Fibers. 2000. Review of the U.S. Navy's Exposure Standard for Manufactured Vitreous Fibers. National Academy of Sciences, National Research Council, Washington, D.C.: National Academy Press. 24. Lee, I-Min, et al, "Man-made Vitreous Fibers and Risk of Respiratory System Cancer: A Review of the Epidemiologic Evidence" 37 J. Occup. \& Env. Med. 725 (1995). 
25. Labor, United States Department of (2005), Occupational Safety \& Health Administration, Chemical Sampling Information, CAS Registry Number: 65997-17-3 (Fibrous Glass)

26. North American Insulation Manufacturers Association ("NAIMA"), Insulation Facts \#62 "Health and Safety Facts for Fiber Glass", Pub. No. N040, May 2012.

27.Corning, Owens (2007), Fiberglass Thermal Batt, Product Data Sheet, retrieved 2012-02-23. 